\title{
Analysis of Microbiological Results in Teeth with Chronic Apical Periodontitis
}

\author{
Angela Gusiyska ${ }^{a}$, Stefan Peev ${ }^{b}$ \\ ${ }^{a}$ Assistant Professor of the Department of Conservative Dentistry, Faculty of Dental Medicine, Medical University-Sofia, Bulgaria \\ ${ }^{\mathrm{b}}$ Associate Professor of the Department of Periodontology and Dental Implantology, Faculty of Dental Medicine, Medical University - \\ Varna, Bulgaria
}

\begin{abstract}
The invasion of the living microorganisms and their toxic products in endodontium and periapical structures is a significant problem in chronic apical periodontitis (CAP).This study analyzed the microbiological results of teeth with CAP.Microorganisms were isolated from the infected root canals of teeth with chronic apical periodontitis (primary or secondary) with or without the absence of clinical signs and symptoms. The microbiological diagnosis was made based on 79 teeth from 79 patients who fulfilled the inclusion criteria (n=79; 38 single-rooted and 41 multi-rooted teeth/36 females and 43 males) with an average age of 40 years (age range $=18$ 62). The study investigated teeth with $C A P$ with or without an endodontic treatment. The data was inputted and processed using statistical package SPSS 15.0.1.E. faecalis was the most frequently isolated microorganism (68.6\%). The analysis of microbiological results in primary CAP (Group II) showed that there were no isolated microorganisms in $78.6 \%$ of the cases (22 cases). In contrast, in Group I, the first microbiological sample results were positive, with bacterial growth at $92.2 \%$ (47 cases).E. faecalis is a typical microflora in persistent CAPs performed with unsatisfactory endodontic treatment, and it is not isolated from teeth with primary CAP. E. faecalis is a resistant microorganism even after the application of chemomechanical preparation of the endodontic space.
\end{abstract}

Keywords: endodontics, enterococcus faecalis, microbiological analysis, periapical periodontitis, retreatment.

\section{Introduction}

The dynamic relationship between microorganisms with macroorganisms in infected radicular pulp tissue and periodontal ligaments is defined as local inflammation with typical signs of hard tissue resorption. This induces destruction of the periapical tissues and the formation of lesions in various stages of histopathological development. These chronic apical periodontitis (CAPs) are often referred to as periapical lesions [6,27]. The aim of contemporary endodontic retreatment is to ensure maximum successful regeneration of periapical structures by instrumentation of the root canal at the first appointment. This should be followed by the long-term intracanal application of a calcium hydroxide dressing for one week. CAPs are the result of an inflammatory process in the periapical tissues initialized by nonspecific inflammatory and specific immunological responses to an infection in the endodontic space. Treatment is based on eliminating the microbes and their toxic products from the root canal, therefore removing the stimulus for either the cause or the persistence of CAP. The achieved degree of a maximum decontamination should be followed by an exact three-dimensional obturation of the endodontic space, which would prevent subsequent recontamination. Despite modern improvements in techniques, armamentarium, medicaments, and materials, a large percentage of CAPs are still the result of endodontic treatment that has already been performed. The frequency of CAP ranged from $2-10.5 \%$ in the study populations of several papers $[1,3,16]$. Some authors reported that CAP was found in $67.5 \%$ of the total number of studied devitalized teeth. He noted that the most common reasons for endodontic failure were the influence of microleakage and the unsatisfactory obturation of root canals $[12,30]$.

This present study aimed to analyze the microbiological results of teeth with CAP. The microorganisms were isolated from the infected root canals of teeth with chronic apical periodontitis (primary or secondary) with or without the presence of clinical signs and symptoms.

\section{Material and Methods}

The microbiological diagnosis was made on 79 teeth $(n=79$; 38 single-rooted and 41 multi-rooted) of 79 patients (36 females and 43 males) with an average age of 40 years (age range $=18-62$ ) that met the inclusion criteria. The present study investigated teeth with chronic apical periodontitis (CAP) with or without an endodontic treatment. The criteria for inclusion of the patients in this clinical study were: lack of diagnosed common systemic diseases, lack of treatment with antibiotics in the last two months if endodontic treatment had been performed more than 12 months prior to the study. The clinical cases were grouped into two main groups. Group I consisted of teeth with chronic periapical lesions with primary endodontic treatment $(n=51)$; Group II consisted of teeth with periapical lesions without endodontic treatment $(n=28)$. All microbiological tests were performed at the same laboratory, /Cibalab, Sofia, Bulgaria/, in order to avoid discrepancies in results obtained from using different laboratories.

The clinical protocol included: removal of tartar and plaque, isolation of the operative field with a rubber dam, and disinfection of the operative field.After disclosure of the pulp chamber and/or removal of the sealer, the first sample was taken from the root canal with sterile paper points and was placed in a transport medium. The treatment protocol included a crown-down hybrid processing technique and an irrigation protocol with the application of the $5.25 \% \mathrm{NaOCl}$ (activated with passive ultrasonic irrigation equipment), $17 \%$ EDTA, $40 \%$ citric acid, and $0.9 \% \mathrm{NaCl}$ as the finalrrigation. 


\section{International Journal of Science and Research (IJSR) \\ ISSN (Online): 2319-7064 \\ Index Copernicus Value (2013): 6.14 | Impact Factor (2014): 5.611}

In cases of endodontretreatment, Endosolv E (Septodont, France) and Endosolv R (Septodont, France) were used to remove the old canal filling. Afterinstrumentation of the root canal system, asecond microbiological sample was taken using sterile paper points; it was then placed in a transport medium (VMGA III gel). The endodontic access was sealed with a pellet in the pulp chamber with chlorhexidine $(2 \%)$ and with a temporary filling. In 37 of the clinical cases, the endodontic treatment was performed over the course of twoappointments. In 42 of the clinical cases, the endodontic treatment was performed over the course of multiple appointments. This required the formation of two subgroups for each group: Subgroup A, the two-appointment treatment group, and Subgroup B, the multi-appointment treatment group.

\section{Results}

In 53 of the clinical cases of CAP, the first microbiological sample was positive $(67.08 \%)$. Isolated microorganisms, mainly anaerobic microflora, confirmed the nature of the pathological changes in periapex-persistent chronic infection. Analysis of the microbiological results showed that the microorganisms were isolated in $78.6 \%$ of the primary CAP cases $(n=22)$ (Group II).

Ricucci, et al.(2006) published similar results by analyzing 50 cases of primary CAP, and microorganisms were not detected in $32(64 \%)$ of those cases [21]. If the microorganisms were not eliminated during preparation of the endodontic space, the dentin tubules were invaded and the microorganism reinfected the root canal. In contrast to the Group II results, the first microbiological sample in Group I was positive for bacterial growth (92.2\% [47 cases]).E. faecalis is the most common microorganism isolated from the root canal in secondary CAP (Group I; $68.6 \%$ ). This high percentage demonstrates the microorganism's ability to penetrate into the dentin tubules, to adhere strongly to collagen, and to resist the irrigation solutions used in the endodontic treatment protocol. The study results are evaluated and tabulated in Table 1 and Table 2.

Analysis of the results showed a statistically significant reduction of the microorganisms isolated in the second microbiological sample (after instrumentation of the root canal system and before the planned definitive obturation) (Table 2).

Table 1: Comparison of percentage shares of Group I and II after the first microbiological sample

\begin{tabular}{|c|c|c|c|c|}
\hline $\begin{array}{c}\text { Isolated } \\
\text { microorganisms }\end{array}$ & Code & $\begin{array}{c}\text { Descriptive statistics (Group I) } \\
n=51\end{array}$ & $\begin{array}{c}\text { Descriptive statistics (Group II) } \\
n=28\end{array}$ & $\begin{array}{c}\text { Comparison of percentage } \\
\text { Shares into two groups }\end{array}$ \\
\hline Enterococcus faecalis & 1 & $68.6 \%(35 \mathrm{cases})$ & - & $\mathrm{P}=0.000$ \\
\hline Streptococcus species & 2 & $50.9 \%(26 \mathrm{cases})$ & $17.8 \%(5$ cases $)$ & $\mathrm{P}=0.008$ \\
\hline Pseudomonas aeruginosa & 3 & $37.3 \%(19 \mathrm{cases})$ & - & $\mathrm{P}=0.000$ \\
\hline Prevotella intermedia & 4 & $21.6 \%(11 \mathrm{cases})$ & $10.7 \%(3$ cases $)$ & $\mathrm{P}=0.360$ \\
\hline Candida albicans & 5 & $31.4 \%(16 \mathrm{cases})$ & $7.1 \%(2$ cases $)$ & $\mathrm{P}=0.029$ \\
\hline Porphyromonas gingivalis & 6 & $19.6 \%(10 \mathrm{cases})$ & $21.4 \%(6$ cases $)$ & $\mathrm{P}=0.910$ \\
\hline Protens Mirabili & 7 & $3.92 \%(2$ cases $)$ & - & $\mathrm{P}=0,000$ \\
\hline Peptostreptococcus micros & 8 & $3.92 \%(2$ cases $)$ & - & $\mathrm{P}=0.000$ \\
\hline Negative samples & & $7.8 \%(4$ cases $)$ & $78.6 \%(22 \mathrm{cases})$ & $\mathrm{P}=0.000$ \\
\hline
\end{tabular}

$\mathbf{n}=$ number of teeth

Table 2: Comparison of percentage shares of Group I and II after the second microbiological sample.

\begin{tabular}{|c|c|c|c|c|c|c|}
\hline Isolated microorganisms & Code & \multicolumn{2}{c|}{$\begin{array}{c}\text { Descriptive statistics } \\
\text { (Group I) } \mathrm{n}=51\end{array}$} & \multicolumn{2}{c|}{$\begin{array}{c}\text { Descriptive statistics } \\
\text { (Group II)n=28 }\end{array}$} & $\begin{array}{c}\text { Comparison of percentage shares } \\
\text { into two groups }\end{array}$ \\
\hline & & $\begin{array}{c}\mathrm{A} \\
n=18\end{array}$ & $\begin{array}{c}n=33 \\
\mathrm{~B}\end{array}$ & $\begin{array}{c}\mathrm{A} \\
n=19\end{array}$ & $\begin{array}{c}\mathrm{B} \\
n=9\end{array}$ & $\mathrm{P}=0.000$ \\
\hline Enterococcus faecalis & 1 & - & $17.64 \%(9)$ & - & - & $\mathrm{P}=0.000$ \\
\hline Streptococcus species & 2 & - & $5.8 \%(3)$ & - & $1.96 \%(1)$ & $\mathrm{P}=0.000$ \\
\hline Pseudomonas Aeruginosa & 3 & - & $3.92 \%(2)$ & - & - & $\mathrm{P}=0.000$ \\
\hline Prevotella intermedia & 4 & - & $1.96 \%(1)$ & - & $1.96 \%(1)$ & $\mathrm{P}=0.000$ \\
\hline Candida albicans & 5 & - & $3.92 \%(2)$ & - & & $\mathrm{P}=0.000$ \\
\hline Porphyromonas gingivalis & 6 & - & 0 & - & $3.92 \%(2)$ & $\mathrm{P}=0.000$ \\
\hline Protens Mirabili & 7 & - & 0 & - & - & $\mathrm{P}=0.000$ \\
\hline Peptostreptococcus micros & 8 & - & $1.96 \%(1)$ & - & - & $\mathrm{P}=0.000$ \\
\hline Positive samples & & - & $35.29 \%(18$ cases) & & $14.28 \%$ (4cases) & \\
\hline
\end{tabular}

$\mathbf{n}=$ number of teeth; $\mathbf{A}=$ Subgroup A; $\mathbf{B}=$ Subgroup B.

Table 3: Comparison of percentage shares into Group I.

\begin{tabular}{|l|l|l|l|l|l|l|l|l|}
\hline & A1 & A2 & A3 & A4 & A5 & A6 & A7 & A7 \\
\hline A1 & & & X & X & X & X & X & X \\
\hline A2 & & & & X & & X & X & X \\
\hline $\mathbf{A 3}$ & X & & & & & & X & X \\
\hline A4 & X & X & & & & & X & X \\
\hline A5 & X & & & & & & X & X \\
\hline A6 & X & X & & & & & X & X \\
\hline A7 & X & X & X & X & X & X & & \\
\hline A8 & X & X & X & X & X & X & & \\
\hline
\end{tabular}

Volume 5 Issue 2, February 2016

www.ijsr.net 


\section{International Journal of Science and Research (IJSR) ISSN (Online): 2319-7064 \\ Index Copernicus Value (2013): 6.14 | Impact Factor (2014): 5.611}

A - Group I; 1-8 - codes of microorganisms: 1 - E. Faecalis; 2 - Str. species; 3 - Pseudomonas aeruginosa; 4 - Prevotella intermedia; 5 - C. albicans; 6 - Porphyromonas gingivalis; 7 - Protens Mirabili; 8 - Peptostretococcus micros; X statistically significant difference.

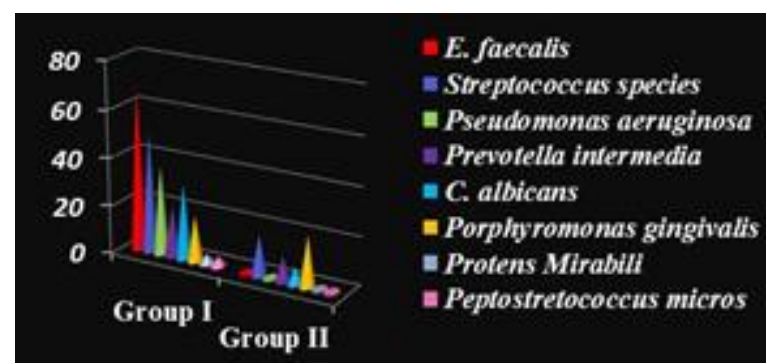

Figure 1: Distribution of microorganisms in both groups studied.

The samples with isolated microorganisms in Group I (35.29\%; 18 cases) and Group II(14.28\%; 4 cases) formed the basis for the creation of two subgroups for each ofthe two study groups. The samples with isolated microorganisms in Group I (35.29\%; 18 cases) and Group II $(14.28 \% ; 4$ cases) formed the basis for the creation of two subgroups for each of the two studygroups. This was the case for the two major groups of positive results. A multiappointment treatment was performed for optimal decontamination. The results are presented in Figure 1.In Group I, no statistically significant differences in percentages were found for the various isolated microorganisms, coded "X" (Table 3), using the chi-square test.Statistic processing of the results showed that the isolation of Protens Mirabili (3.92\%) and Peptostretococcus micros $(3.92 \%)$ could not be applied to microorganisms typically presented in persistent CAP with unsatisfactory endodontic treatment $(p=0.491)$. The resistance of $E$. faecalis at a higher $\mathrm{pH}$ (capable of development at a $\mathrm{pH}$ of 9.6 and tolerant even at a $\mathrm{pH}$ of 12.1) suggested that a highly alkaline environment increases the microorganism's ability to adhere to type I collagen.

\section{Discussion}

Over a century ago, Miller (1890) proved that several different types of bacteria are present in necrotic pulp tissue. Half a century later, Kakehashi, Stanley and Pitzgerald(1965) proved that they do not develop in the sterile pulp chambers of rabbits in an oral environment [14]. These rabbits were compared with the rabbits in the control group that were exposed to conventional oral microflora and which developed massive periapical lesions. Soon after, the importance of obligate anaerobes in endodontic infection was identified[19]. Endodontic infection arises from normal oral microflora in the presence of predisposing factors (pulp necrosis, removal of the pulp tissue in the process of endodontic treatment, and microleakage).

There are approximately 700 microorganism species in the oral cavity, and 20-40 of these are isolated from teeth with periapical lesions. Due to these scientific findings, new methods for maximum decontamination are continuously being investigated [8]. The size of the lesion is most likely in direct proportion to the number of isolated bacterial species and cells of the root canal [25]. Usually, one to five different types of microorganisms are found in persistent apical periodontitis after a root canal treatment and exact root canal obturation. In teeth with inadequate root canal treatment, up to 30 different types of microorganisms have been found to cause primary infections [26]. In periapical lesions, the inflammatory process can be divided into primary inflammation and secondary (persistent) inflammation. Primary inflammation is dominated by the presence of a variety of Gram-negative bacteria, and this makes it difficult to analyze this type of inflammatory process using conventional microbiological methods. Today, these microorganisms are isolated and proven using molecular methods.

To treat CAP, each stage of the decontamination process is associated with the choice of treatment protocol, resulting in the formation of a negative microbiological test before definitive obturation of the root canal can be determined. If this is achieved in the process of treatment, a higher percentage of success can be expected in teeth with CAP. The relationship between CAP and the bacterial infection of the root canal system has been established [5]. In recent decades, research and development in the field of decontamination of the endodontic space have shown that instrumentation is a critical stage in this process. Peters, et al.(2001)showed that $35 \%$ of the walls of the endodontic space remain untreated during mechanical preparation due to the difficulties associated with instrumentation of the canals [20]. Dalton, et al. (1998) assumed that mechanical instrumentation, even without chemical agents for disinfection, reduces the microbial count by more than $90 \%$, which allows mechanical instrumentation to be considered as the primary method for effective decontamination [2].Moreover, in vitro studies have provided evidence of the ability of E. faecalis to adhere to collagen and to penetrate into dentinal tubules in medium with increasing alkalinity, even at a $\mathrm{pH}$ of 8.5 , as a temporary medication with $\mathrm{Ca}(\mathrm{OH})_{2}$. Calcium hydroxide is a medicament with a strong antimicrobial effect, but in conditions of direct contact with microorganisms, certain restrictions impact its effectiveness. First, the dentine has an inhibitory effect on $\mathrm{Ca}(\mathrm{OH})_{2}$; second, different concentrations affect the irrigation solutions; and third, the effectiveness of the preparation in the apical zone decreases $[9,11] . \mathrm{Ca}(\mathrm{OH})_{2}$ is still the only medicament with active alkalization of the endodontic space that can inhibit endotoxins and cause resorption in the outer root surface $[10,13,15]$.Microbiological examination is targeted to $E$. faecalis for two reasons. First, these microorganisms are most frequently isolated from clinical cases of unsuccessful primary endodontic treatment $[18,24,29]$. Second, several virulence factors create difficulties associated with the removal of the $E$. faecalis network from tubular dentin. These virulence factors include proton pumps [4], which have the ability to exist in an environment without nutrients for a long period of time [22] as well as the ability to inhibit the function of Th-1 and Th-2 cells that secrete cytokines [23], the binding to collagen [17], and the resistance to $\mathrm{Ca}(\mathrm{OH})_{2}$. E. faecalis has the increased tendency to penetrate dentinal tubules (700 $1000 \mu \mathrm{m})$. This was found in the study conducted by Haapasalo, et al. [11], and it was confirmed by SEM 


\section{International Journal of Science and Research (IJSR) \\ ISSN (Online): 2319-7064 \\ Index Copernicus Value (2013): 6.14 | Impact Factor (2014): 5.611}

samples from another researcher[9].The proven ability of $E$. faecalis to penetrate into dentinal tubules [18,28], strongly adhere to collagen [17], and resist the irrigation solutions used in the endodontic treatment protocol, were confirmed by the results obtained in this work. After chemomechanical preparation. the percentage of isolated E. faecalis was $17.64 \%$. Gomes et al.(2003) determined that, even after treatment with $\mathrm{NaOCl}(5.25 \%)$ and $\mathrm{Ca}(\mathrm{OH}) 2(\mathrm{pH}=12), E$. faecalis is a microorganism with the highest resistance to chemomechanical preparation of the root canal system [7].

In addition, we speculate that in spite the fact that scientific papers have observed a low success rate for endodontic retreatment, the prevailing data shows that the success rate is higher than the rate of teeth treatments with negative samples relative to E. faecalis. This concurs with the results of the present study.

\section{Conclusion}

E. faecalis was the most frequently isolated microorganism in this present study $(68.6 \%)$. It was isolated from teeth with CAP and teeth with unsatisfactory endodontic treatment. $E$. faecalis is a typical microflora in persistent CAPs performed with unsatisfactory endodontic treatment, and it was not isolated from teeth with primary CAP. E. faecalis is a resistant microorganism even after chemo-mechanical preparation of the endodontic space. The analysis of microbiological results for primary CAP (Group II) shows that, in $78.6 \%$ of the cases $(n=22)$, no microorganisms were isolated. In contrast to the results from Group II, the first microbiological sample in Group I showed positive bacterial growth in $92.2 \%$ of the cases $(n=47)$.

\section{Acknowledgments}

Theauthors deny any conflicts of interest related to this study.

\section{References}

[1] BoucherY, Matossian L, Rilliard F, MachtouP. Radiographic evaluation of the prevalences and technical quality of root canal treatment in a French subpopulation. Int. Endod J 2002;35(3): 229-38.

[2] DaltonB, Ørstavik D, Phillips C, Pettiette M, Trope M. Bacterial reduction with nickel-titanium rotary instrumentation. J Endod1998;24:763-767.

[3] De MoorR, Hommez G, De Boever J,Delmé K, Martens G. Periapical health related to the quality of root canal treatment in a Belgian population. Int Endod J2000;33:113-120.

[4] EvansM, Davies J, Sundqvist G, Figdor D. Mechanisms involved in the resistance of Enterococcus faecalis to calcium hydroxide. Int Endod J 2002; 35: 221-8.

[5] Fabricius L,Dahlén G, Sundqvist G, Happonen R, Möller A. Influence of residual bacteria on periapical tissue healing after chemomechanical treatment and root filling of experimentally infected monkey teeth. Eur J Oral Sci 2006;114:278-285.
[6] Fernandes M, De Ataide I. Non-surgical management of a large periapical lesion using a simple aspiration technique: a case report. Int EndodJ2010; 43: 536-542.

[7] Gomes B, Souza S, Ferraz C, Teixeira F, Zaia A, Valdrighi L, et al. Effectiveness of $2 \%$ chlorhexidine gel and calcium hydroxide against Enterococcus faecalis in bovine root dentine in vitro. Int Endod J2003; 36: 267-275.

[8] Gueorgieva T, DimitrovSl, Dogandhiyska V, Kalchinov V, Belcheva M, Mantareva V, et al. Susceptibility of S. aureus to Methylene BluHaematoporphyrin, Phtalocyanines Photodynamic Effects. Journal of IMAB 2010;16(4):54-56.

[9] Gusiyska A. Orthograde treatment of chronic apical periodontitis - biological approaches. $\mathrm{PhD}$ Thesis, Medical University, FDM-Sofia, 2012, pp.254.

[10] GulabivalaK, Patel B,Evans G, Ng Y. Effects of mechanical and chemical procedures on root canal surfaces. Endod Topics2005; 10: 103-122.

[11] Haapasalo H, Sirén E, Waltimo T,Orstavik D, Haapasalo M. Inactivation of local root canal medicaments by dentine: an in vitro study. Int EndodJ 2000;33:126-131.

[12] Hommez G, Coppens C, De Moor R. Periapical health related to the quality of coronal restorations and root fillings. Int Endod J 2002; 35: 680-689.

[13] JiangJ, Zuo J, Chen S, Holiday L. Calciumhydroxide reduces lipopolysaccaride-stimulated osteoclast formation. Oral Surg Oral Med Oral Pathol Oral RadiolEndod 2003; 95: 348-54.

[14] Kakehashi S, Stanley H, Pitzgerald R. The effects of surgical exposures of dental pulps in germ-free conventional laboratory rats.Oral Surg Oral Med Oral Pathol 1965; 20: 340-9.

[15] Katebzadeh N, Sigurdsson A, Trope M. Radiographic evaluation of periapical healing after obturation of infected root canals: an in vivo study. Int Endod J 2000; 33: 60-66.

[16] Kirkevang L, Ørstavik D, Hörsted-Bindslev P, Wenzel A. Periapical status and quality of root fillings and coronal restorations in a Danish population. Int Endod J 2000; 33: 509-515.

[17] Love R. Enterococcus faecalis - a mechanism for its role in endodontic failure. Int Endod J 2001; 34: 399405.

[18] Molander A, Reit C, Dahlén G, Kvist T. Microbiological status of root filled teeth with apical periodontitis. Int Endod J 1998; 31:1-7.

[19] Möller A. Microbiological examination of root canals and periapical tissues of human teeth.OdontolTidskr1966; 74:1-38.

[20] Peters L, Wesselink P, Buijs J,Winkelhoff A. Viable Bacteria in root dentinal tubules of teeth with apical periodontitis. J Endod2001; 27 (2):76-81.

[21] Ricucci D, Pascon E, Ford T, Langeland K.Epithelium and bacteria in periapical lesions. Oral Surg. Oral Med. Oral Pathol. Oral Radiol. Endod., 2006, 101, № 2, 239 249.

[22] Sedgley C, Lennan S, Appelbe O. Survival of Enterococcus faecalis in root canals ex vivo. Int Endod J 2005; 38:735-742.

[23] Sheely E, Roberts G. Use of calcium hydroxide for apical barrier formation and healing in non-vital 


\section{International Journal of Science and Research (IJSR) \\ ISSN (Online): 2319-7064}

Index Copernicus Value (2013): 6.14 | Impact Factor (2014): 5.611

immature permanent teeth: A review. $\mathrm{Br}$ Dent $\mathrm{J}$ 1997;183:241-6.

[24] Siqueira J, Jose F. Endodontic infections: concepts, paradigms, and perspectives. Oral Surg Oral Med Oral Pathol Oral Radiol Endod 2002; 4(3):281-93.

[25] Siqueira J, Rôças I, Alves F,Campos L. Periradicular status related to the quality of coronal restorations and root canal fillings in a Brazilian population. Oral Surg Oral MedOral Pathol Oral Radiol Endod 2005;100:36974.

[26] Siqueira J, Rôças I. Distinctive features of the microbiota associated with different forms of apical periodontitis. J Oral Microbiol 2009; 8: 1-10.

[27] Soares J,Santos S, César C, Silva P, Sá M, Silveira F, et al. Calcium hydroxide induced apexification with apical root development: a clinical case report. Int J Endod 2008; 41(8):710-719.

[28] Stübinger S, Sader R, Filippi A. The use of ozone in dentistry and maxillofacial surgery: a review. Quintessence Int2006; 37(5):353-9.

[29] Sundqvist G, Figdor D. Endodontic treatment of apical periodontitis. In: Ørstavik, D., T. R. Pitt Ford, eds. Essential Endodontology. Prevention and Treatment of Apical Periodontitis. Oxford: Blackwell Science, 1998, 242-277.

[30] Tay F, Loushine R, Weller R, Kimbrough W, Pashley $\mathrm{D}$, Mak Y, et al.Ultrastructural evaluation of the apical seal in roots filled with a polycaprolactone-based root canal filling material. J Endod 2005; 31(7):514-518. 